\title{
ANTROPOLOGIA FILOSÓFICA: UM PARALELO ENTRE O PENSAMENTO HEIDEGGERIANO E O SCHELERIANO EM BUSCA DO SER DO HOMEM
}

\author{
Philosophical anthropology: a parallel between Heidegger's thought and scheleriano in \\ search of man's being
}

\section{Leila Rosibeli Klaus *}

Resumo: O objetivo do trabalho é comparar os pensamentos de Heidegger e de Scheler sobre a questão ontológica do homem. Para tal, apresentase como pano de fundo o mundo na qual o homem já sempre se encontra. As principais obras aqui exploradas são "Ser e Tempo" de Heidegger e "A Posição do Homem no Cosmos de Scheler". Faz-se essencial no desenvolvimento do objetivo supracitado verificar o posicionamento de Heidegger em relação ao pensamento antropológico no interior de sua obra "Ser e Tempo". Além disso, é fundamental mostrar como a antropologia filosófica constituiu a meta principal nos escritos de Scheler, com a introdução da pessoa. Toda essa análise tem como justificativa apresentar a situação da antropologia filosófica no século XX, que tenta encontrar um lugar seguro no interior da filosofia.

Palavras-chave: Antropologia filosófica, Heidegger, Ontologia, Scheler.
Abstract: The objective is to compare the thoughts of Heidegger and Scheler on the ontological question of man. To this end, the world in which the man was always found introduces itself as background. This paper's main works are Heidegger's "Being and Time" and Scheler's "The human place in cosmos". It is essencial in the development of the aforementioned objective to verify Heidegger's position towards anthropological thought inside his work "Being and Time". Also in the same philosophical period, it is fundamental to show how anthropological philosophy constitutes the main aim in Scheler's writings with the introduction of person. All this analysis is justified introducing the situation of philosophical anthropology in the 20th century that tries to find a safe place inside philosophy. Keywords: Philosophical anthropology, Heidegger, Ontology, Scheler.

* Mestre em Filosofia pela Universidade Federal de Santa Maria (UFSM).

\begin{tabular}{|c|c|l|l|c|c|}
\hline intuitio & $\begin{array}{c}\text { ISSN } \\
1983-4012\end{array}$ & Porto Alegre & Vol.8 $-\mathrm{N}^{\mathrm{o}} .2$ & $\begin{array}{c}\text { Dezembro } \\
2015\end{array}$ & p.128-145 \\
\hline
\end{tabular}


Antropologia filosófica: um paralelo entre o pensamento heideggeriano e o scheleriano em busca do ser do homem

\section{Introdução}

Na Alemanha, em torno do final do século XIX, surge a antropologia filosófica através de um pensamento que tem como base uma ciência empírica e a filosofia. A fim de responder a pergunta "o que é o homem?" esse novo pensamento teria um recíproco ganho teórico, pois na medida em que a questão filosófica teria uma base empírica, esta poderia sanar algumas necessidades filosóficas acerca do homem. A obra que demarca essa nova posição do pensamento filosófico é A Posição do Homem no Cosmos (1928) de Scheler. Tal pensamento encontrou uma oposição nos escritos heideggerianos de $1929^{1}$, nos quais Heidegger se dirige a quarta pergunta elaborada por Kant na sua obra Crítica da razão pura. Esta quarta pergunta tem um teor puramente antropológico e para Kant ela seria responsável por fundamentar o verdadeiro resultado da metafísica, entretanto, Heidegger combate esta ideia kantiana afirmando que a antropologia pode ser elaborada apenas como uma ontologia regional. Mesmo com o distanciamento de Heidegger a este novo pensamento filosófico, a filosofia pós Hegel necessitava de novas ideias para superar sua perda de identidade, dado o contexto das ciências positivistas. É por essa perspectiva que a pergunta “o que é o homem?" merece um desenvolvimento apropriado para rever um pensamento filosófico que estava às sombras das ciências naturais e do historicismo.

Diante disto, é com Scheler que a antropologia se torna uma disciplina filosófica que procura a essência que todas ciências empíricas rejeitavam, a saber, a do homem e de seu lugar no interior do ser. Scheler desenvolve uma investigação essencialista, que girava em torno da essência do homem. Esta, por sua vez, é definida a partir de uma investigação descritiva, ou seja, não se sabe o que o homem é, mas sabemos o que ele não é, atribuindo, dessa forma, um caráter interpretativo para análise da essência do homem. Diante da crise da filosofia e do contexto histórico entre guerras, para Scheler a antropologia filosófica significava a história da autoconsciência do homem, isto é, buscar, perante as ciências empíricas, uma auto certeza interpretativa a partir de um método reflexivo de autocompreensão. Mesmo as ciências empíricas dominando as investigações acerca dos conhecimentos em geral, Scheler encontra uma maneira de construir uma disciplina filosófica do homem sem rejeitar tais ciências, a partir da psicologia e da biologia, ele inicia a descrição da vida para concluir que a diferença entre o animal e o homem não é dada no âmbito das ciências empíricas, mas sim num contexto filosófico onde a diferença entre ambos não é de grau racional ou de capacidade técnica, mas de autocompreensão. A ideia de homem engloba o viver e fazer humanos do mesmo modo que se refere ao ser e a essência humana. Esta última é espiritual e depende da esfera vital, não há no pensamento de Scheler uma essência humana totalmente desligada do contexto vital e existente.

\footnotetext{
${ }^{1}$ HEIDEGGER, M. Kant y el Problema de la Metafísica. $3^{\text {a }}$ edição. México: Fondo de Cultura Econômica, 1996.
}

\begin{tabular}{|c|c|l|l|c|c|}
\hline intuitio & $\begin{array}{c}\text { ISSN } \\
1983-4012\end{array}$ & Porto Alegre & Vol.8 $-\mathrm{N}^{\mathrm{o} .2}$ & $\begin{array}{c}\text { Dezembro } \\
2015\end{array}$ & p.128-145 \\
\hline
\end{tabular}


Antropologia filosófica: um paralelo entre o pensamento heideggeriano e o scheleriano em busca do ser do homem

A preocupação antropológica filosófica presente nos escritos tardios de Scheler procuram uma ideia unitária de ser humano e seu lugar no ser originário, atribuindo dessa forma, uma preocupação ontológica que até então era secundária nas suas obras. Scheler introduz uma nova ontologia em comparação com a ontologia de Heidegger. A novidade ontológica de Scheler diz respeito a seu não fundamentalismo, isto é, em Heidegger a ontologia era a base para toda e qualquer investigação filosófica, já para Scheler a investigação ontológica pressupõe uma base antropológica e filosófica. Segundo Scheler, a ontologia só pode ser alcançada com uma ampla busca pelo homem, ou pode-se ainda, a ontologia e a antropologia filosófica se complementarem na explicação do homem e de seu lugar no cosmos. Já por outro lado, sabemos que no pensamento heideggeriano a ontologia é o foco da investigação como algo fundamental, colocando a questão do ser em um patamar que, de acordo com Heidegger, até então não havia ocorrido em toda a história da filosofia. É evidente, pois, que os escritos de Heidegger se afastam de qualquer tipo de investigação com teor antropológico, jamais a ontologia teria pressuposto antropológico; ao contrário, o que encontramos em Ser e Tempo é a pretensão de localizar o lugar da ontologia fundamental no interior da filosofia. Para tanto, o filósofo percorre uma linha interpretativa que inicia com a pergunta pelo ser, a qual culmina num lugar especial que é a existência e o acontecer do Dasein. A essência deste ente se baseia na sua existência, se trata do homem concreto que existe como Dasein. Ademais, segundo Heidegger, não é possível a antropologia filosófica scheleriana constituir-se como disciplina fundamental da filosofia, porque as perguntas da antropologia não são suficientemente radicais e ainda são incompatíveis com a filosofia. Parece, por fim, que seria necessário resgatar a antropologia filosófica de Scheler, pois diante da crise de identidade da filosofa, diante da rica ontologia fundamental de Heidegger e de tantas outras filosofias, ela enfraqueceu-se, de modo a ser tida como uma disciplina incapaz de fundamentos filosóficos para um ser tão plural quanto o homem.

\section{O posicionamento de Heidegger diante da Antropologia filosófica e a construção de tal pensamento no interior da filosofia}

O primeiro período do pensamento de Scheler constitui-se por obras acerca da concepção religiosa e da ética, elas marcam do período entre 1913 a 1922. Em sua obra O formalismo na ética e a ética material dos valores de 1913/16, cujo título original é Der Formalismus in der Ethik und die materiale Wertethik $^{2}$, Scheler caracteriza o ser humano como um conjunto de atos ou vivências, como uma unidade e identidade não substancial, ou seja, sendo realização de atos o ser humano não pode ser definido como uma coisa ou substância. Por isso, é da essência do homem nunca tornar-se objeto de um ato de reflexão

\footnotetext{
${ }^{2} \mathrm{Na}$ tradução espanhola a obra é intitulada como Ética.
}

\begin{tabular}{|c|c|c|c|c|c|}
\hline intuitio & $\begin{array}{c}\text { ISSN } \\
1983-4012\end{array}$ & Porto Alegre & Vol.8 $-\mathrm{N}^{\mathrm{o}} .2$ & $\begin{array}{c}\text { Dezembro } \\
2015\end{array}$ & p.128-145 \\
\hline
\end{tabular}


Antropologia filosófica: um paralelo entre o pensamento heideggeriano e o scheleriano em busca do ser do homem

ou tornar-se algo objetivável; ao invés disso, o ser humano é passível de ser amado já que é capaz de despertar afetos. Ainda nesse mesmo período, mas em outra obra, a saber, Essência e formas da Simpatia de 1913/1922, ou ainda, Wesen und Formen der Sympathie, é que Scheler desenvolve a ideia dos afetos ao introduzir a unificação afetiva como nova forma de simpatia. Nesse contexto o tema do amor é tido, entre outros, como o mais importante, visto que é um sentimento emocional originário que torna o homem "amável" e passível de amar. No entanto, embora os primeiros escritos de Scheler constituem uma parte importante do seu pensamento, é na segunda fase de seus escritos que nos centramos a partir de agora.

A segunda época do pensamento de Scheler, após 1922, apoia-se no tema da antropologia filosófica. Também nesta mesma época ele retoma a filosofia da religião, que iniciou com seu conjunto de obras, em 1921, intitulado Do eterno no homem ou Vom Ewigen im Menschen. Apesar do empreendimento para escrever sobre a antropologia filosófica, Scheler falece em 24 de maio de 1928, após escrever sua obra central que girava em torno da essência do homem: A Posição do Homem no Cosmos ou Die Stellung des Menschen im Kosmos de 1928. Esta obra marca uma nova concepção de homem oposta a todas aquelas já desenvolvidas no interior do pensamento filosófico. A filosofia moderna, por exemplo, compreendia o homem como objeto de conhecimento juntamente com as outras coisas, de modo que o colocava no plano de objeto a ser conhecido, o que ocasionava, de certa forma, uma perda de sentido e uma perda de essencialidade propriamente humana. A antropologia filosófica de Scheler, por outro lado, procura a essência do homem, isto é, busca o todo do fenômeno humano e não visões parciais. Para tanto, Scheler lança mão do conceito de pessoa, a fim de evitar que a antropologia filosófica reduza a ideia de homem à coisificação do homem. Este conceito - pessoa - impede a redução de homem a simples objeto de observação empírica. Além da tradição filosófica colocar o homem como objeto de análise, aparece na obra Kant e o problema da metafísica (1929) de Heidegger, uma crítica não só à teoria kantiana, mas também à teoria filosófica de Scheler. Kant disserta, na sua obra Crítica da Razão Pura, sobre a possibilidade de fundamentar a metafísica na antropologia empírica. A partir de três perguntas atribuídas à metafísica, são elas: o que posso saber?; o que devo fazer?; o que me é permitido esperar?; Kant formula uma quarta: o que é o homem?. Ele afirma que esta última pergunta poderia abarcar todas as três primeiras, justamente porque elas acabam se reestruturando nos parâmetros desta última quarta questão. Heidegger condena esta ideia kantiana ao afirmar que uma investigação sobre a fundamentação da metafísica precisa desenvolver-se no próprio projeto da possibilidade da metafísica. Não se trata de buscar a saída do problema de uma fundamentação da metafísica em um outro âmbito que não seja no interior da própria possibilidade da metafísica. Além disso, de acordo com Heidegger a elaboração de uma

\begin{tabular}{|c|c|l|l|c|c|}
\hline intuitio & $\begin{array}{c}\text { ISSN } \\
1983-4012\end{array}$ & Porto Alegre & Vol.8 $-\mathrm{N}^{\circ} .2$ & $\begin{array}{c}\text { Dezembro } \\
2015\end{array}$ & p.128-145 \\
\hline
\end{tabular}


Antropologia filosófica: um paralelo entre o pensamento heideggeriano e o scheleriano em busca do ser do homem

antropologia diz respeito apenas ao âmbito da ontologia regional, que estuda uma ontologia específica a partir das ciências empíricas ${ }^{3}$.

Já a crítica direta de Heidegger à antropologia filosófica de Scheler ocupa-se da afirmação segundo a qual há uma dificuldade fundamental na elaboração da antropologia filosófica, a saber, a do seu próprio conceito. Ao desaprovar a antropologia filosófica, Heidegger aponta uma imprecisão conceitual, uma obscuridade no formalismo e uma indecisão de regras. Dado que a antropologia filosófica de Scheler nasce no contexto de pós filosofia hegeliana, segue-se que ela não está fundada na essência da própria filosofia; mas sim em uma espécie de receptor de problemas filosóficos. A ideia de Heidegger para a elaboração da antropologia filosófica exige que ela desenvolva-se no interior da analítica do Dasein, isto é, que a antropologia filosófica seja como uma ontologia privativa, que estuda a ontologia regional (ciências empíricas) a partir da analítica existencial. Além das críticas de Heidegger à antropologia filosófica no escrito de 1929, já temos em Ser e Tempo de 1927 o evidente afastamento de qualquer intenção antropológica na elaboração da investigação ontológica. Especialmente no parágrafo 10 de Ser $e$ Tempo que a crítica heideggeriana nos salta aos olhos, pois nela ele afirma que Scheler não colocou a questão do ser da pessoa em si mesmo ${ }^{4}$. Além disso, o filósofo mostra sua desaprovação em relação à teoria scheleriana ao sustentar que antropologia filosófica, com seus temas sobre o personalismo, está repleta de limitações. Assim se lê no seguinte fragmento:

Mesmo a interpretação fenomenológica da personalidade, em princípio mais radical e lúcida, não alcança a dimensão da questão do ser do Dasein. Malgrado todas as diferenças no questionamento, na condução e orientação da concepção de mundo, as interpretações da personalidade elaboradas por Husserl e Scheler concordam e coincidem naquilo que ambos possuem de negativo. Tanto um quanto o outro já não colocam a questão sobre o ser da pessoa em si mesmo ${ }^{5}$.

A crítica heideggeriana dirigida aqui ao Scheler e ao Husserl se refere à ausência de bases ontológicas na ideia de pessoa e na ideia de atos. Para Heidegger ambos os filósofos se afastaram da questão fundamental do ser do Dasein e de um sentido unitário para as ideias de pessoa e de ato. Ao caracterizar a pessoa como a unidade de vivências, Scheler evita que ela seja dada como algo substancial, da mesma maneira Husserl afirma que os atos intencionais nunca podem ser dados como objetos, nem como dados psíquicos. A pessoa, tanto em Scheler como em Husserl, constitui-se a partir de atos

\footnotetext{
${ }^{3}$ HEIDEGGER, M. Kant y el Problema de la Metafísica. $3^{\text {a }}$ edição. México: Fondo de Cultura Econômica, 1996, p. $176 \mathrm{ss}$.

${ }^{4}$ HEIDEGGER, M. Ser e Tempo. Partes I e II. Trad.: Marcia Sá Cavalcante Schuback. Rio de Janeiro: Vozes, 2009, p. 89.

${ }^{5}$ HEIDEGGER, M. Ser e Tempo. Partes I e II. Trad.: Marcia Sá Cavalcante Schuback. Rio de Janeiro: Vozes, 2009, p. 91.
}

\begin{tabular}{|c|c|c|c|c|c|}
\hline intuitio & $\begin{array}{c}\text { ISSN } \\
1983-4012\end{array}$ & Porto Alegre & Vol.8 $-\mathrm{N}^{\mathrm{o} .2}$ & $\begin{array}{c}\text { Dezembro } \\
2015\end{array}$ & p.128-145 \\
\hline
\end{tabular}


Antropologia filosófica: um paralelo entre o pensamento heideggeriano e o scheleriano em busca do ser do homem

intencionais e, portanto, não possui na sua essência objeto algum. Para Heidegger, todavia, falta determinar ontologicamente o modo de ser da pessoa, como se observou na passagem supracitada.

Tendo em vista a crítica de Heidegger a Scheler, sobre uma privação de bases ontológicas na construção do conceito de pessoa, segue-se que na antropologia filosófica de Scheler há uma preocupação ontológica, que até então era secundária nos seus escritos. Ora, temos no segundo período do pensamento de Scheler tanto uma investigação antropológica quanto uma investigação ontológica, de acordo com a ideia de que uma ontologia só poderia ser alcançada com uma ampla análise antropológica. A preocupação ontológica de Scheler, por um fundamento tanto do homem como do cosmos, culmina em um critério único, no qual espírito e vida seriam manifestações exclusivamente do homem. O ser originário, por sua vez, adquiriria consciência de si mesmo no homem. A investigação ontológica, nesse contexto, seria alcançada pressupondo uma base antropológica, ou seja, compreender-se-ia a ontologia a partir da análise da essência do ser do homem. É evidente, por outro lado, que a filosofia heideggeriana procurou encontrar o lugar da ontologia fundamental no interior da filosofia sem depender de uma análise antropológica. Portanto, enquanto Heidegger colocou no centro da filosofia o problema do ser, Scheler deslocou o homem da periferia do pensamento filosófico para uma posição central com a elaboração da antropologia filosófica. O objetivo de Scheler baseia-se na ideia de que qualquer antropologia empírica possua como fundamento a antropologia filosófica e, ainda, que esta dê um caráter antropológico para a filosofia. Do outro lado, como sabemos, Heidegger insistiu, em toda sua obra Ser e Tempo, para que analítica existencial não se assimilasse com qualquer interpretação antropológica.

À primeira vista, a antropologia filosófica pretende analisar e descrever o homem distanciando-o de conhecimentos que abarcam as estruturas concretas nas quais o ser humano vive. Como disciplina que visa encontrar uma forma de falar filosoficamente do homem sem conectar-se com formas contingentes e empíricas, ela precisa buscar uma maneira segundo a qual o homem compreenda a si mesmo e ao mundo, sem o auxílio das ciências naturais, como a biologia, a antropologia e a psicologia. Posteriormente, o método de investigação da antropologia filosófica seria reflexivo do tipo de autocompreensão, que se dá quando o ser humano encontra-se consigo mesmo. Desse modo, Scheler inicia a busca pela compreensão do ser do homem a partir de uma metafísica presente na base da própria existência, entre o saber filosófico e as ciências parciais. Com tal característica, a antropologia filosófica "terá como tarefa ater-se a uma questão fundamental claramente antropológica: a pergunta por quem nós somos propriamente, como seres humanos?"6. Nessa perspectiva, Scheler situa o homem em uma esfera espiritual transcendente e em uma esfera vital. Mas eis que agora essa esfera não é mais ofuscada por instintos primitivos, ou seja, o homem é capaz de reflexão, seja acerca de si mesmo ou do mundo que o cerca na qualidade de pessoa espiritual.

${ }^{6}$ STEIN, E. Antropologia filosófica - Questões Epistemológicas. Ijuí: Unijuí, 2006, p. 43.

\begin{tabular}{|c|c|c|c|c|c|}
\hline intuitio & $\begin{array}{c}\text { ISSN } \\
1983-4012\end{array}$ & Porto Alegre & Vol.8 - No.2 & $\begin{array}{c}\text { Dezembro } \\
2015\end{array}$ & p.128-145 \\
\hline
\end{tabular}


Antropologia filosófica: um paralelo entre o pensamento heideggeriano e o scheleriano em busca do ser do homem

Enquanto tal, o mundo se manifesta um viver humano aprimorado que pode ser contemplado, e cuja função não é mais apenas a reprodução ou a evolução da espécie, mas sim um mundo capaz de objetivação e conhecimento.

\section{A ideia de negação presente nas obras Ser e Tempo e A Posição do Homem no Cosmos}

A obra "Ser e Tempo", foi escrita com o intuito de construir uma ontologia fundamental, buscando a questão do sentindo do ser que há tempos havia sido esquecida pela tradição. Pois bem, é através deste empreendimento que Heidegger investiga se tal questão pode ser colocada de modo plausível, possuindo um método seguro de análise. O método adequado a ser seguido é marcadamente hermenêutico ${ }^{7}$, isto é, a partir de uma base sólida é possível interpretar e investigar se a questão do sentido do ser pode ser analisada. Em busca dessa base segura Heidegger parte do pressuposto que um ente em especial, com a capacidade de compreender o mundo que habita, possa também compreender o problema do sentido do ser. A compreensão do ser, por sua vez, é possível no momento que identificamos o ente enquanto propriamente ele mesmo. Este ente em especial é de saída o Dasein, é o ente que nós mesmos somos, mas Heidegger evitando qualquer terminologia antropológica, se afasta de termos como o de homem ou o de pessoa; pois, como já foi visto, sua investigação é ontológica. No interior da investigação pela busca de um fundamento ontológico, a primeira etapa que Heidegger institui assenta-se em descrever a existência do Dasein, ou seja, como este ente compreende a si mesmo e o mundo circundante. Esta tarefa investigativa Heidegger denomina de analítica existencial. Juntamente com a questão ontológica do Dasein se alcançará toda e qualquer compreensão de ser, portanto, é a partir da existência do ente que nós mesmos somos, no mundo que nós nos encontramos, que a ontologia encontrará seu fundamento. Avancemos, pois, no interior da analítica existencial, entorno da qual o fenômeno da negação se dá.

O Dasein encontra-se em um mundo que já sempre existiu, nesse mundo ele lida com utensílios, conversa com outros entes, vive em sociedade, compreende suas tarefas diárias e se preocupa com outros entes. Heidegger nomeia este modo no qual o Dasein, na maioria das vezes se encontra, de cotidianidade ou de mundanidade. E, para todos os objetos encontrados no mundo, é designado o termo intramundano. A negação no interior do pensamento heideggeriano se dá a partir deste modo cotidiano, isto é, o Dasein renuncia a impropriedade do falatório dos outros entes e a sua lida cotidiana para um modo no qual consiga compreender sua existência mais própria e finita. Para que isso ocorra o Dasein precisa encontrar uma abertura na qual ele consiga se desprender da perdição do modo impessoal. Esta abertura se dá quando o Dasein decide dar ouvidos ao apelo da consciência, um apelo que diante do falatório cotidiano, é

${ }^{7} \mathrm{O}$ método hermenêutico se baseia na interpretação de um horizonte originário. Para Heidegger é primordial alcançar tal horizonte, pois é dele que partirá toda a investigação ontológica.

\begin{tabular}{|c|c|l|l|c|c|}
\hline intuitio & $\begin{array}{c}\text { ISSN } \\
1983-4012\end{array}$ & Porto Alegre & Vol.8 $-\mathrm{N}^{\mathrm{o}} .2$ & $\begin{array}{c}\text { Dezembro } \\
2015\end{array}$ & p.128-145 \\
\hline
\end{tabular}


Antropologia filosófica: um paralelo entre o pensamento heideggeriano e o scheleriano em busca do ser do homem

silencioso e mudo. Quando o Dasein escolhe o silenciar da fala mundana, ele dá ouvidos ao apelo da consciência e adentra na constituição fundamental da existência. Este silêncio, por sua vez, advém da surpresa que o Dasein recebe ao angustiar-se perante seu ser finito.

No entanto, a escolha de negar seu mundo natural que habita não é meramente casual, ela ocorre quando o Dasein antecipa sua morte existencial. Este antecipamento acontece porque estando em dívida consigo mesmo, em dívida com sua própria existência, o Dasein precisa compreender a si mesmo afastando-se da existência fática, a qual não possui respostas para as questões da sua própria existência. Vale destacar aqui, que a questão acerca da dívida, desenvolvida, principalmente, no parágrafo 58 de Ser $e$ Tempo, trata do fundamento para o ser do Dasein. Este fundamento, segundo Heidegger, é desde sempre negativo porque o Dasein está e é um ser em dívida. A negação presente na ontologia heideggeriana leva a termo o conceito de dívida que não pode possuir o significado de débito. Ou ainda, não pode apresentar qualquer sentido vulgar de dever algo à alguém e, além disso, também não pode se referir à culpa moral. Para determinar ontologicamente o ser do Dasein deve-se deixar de lado as ideias de dívida enquanto culpa ao existir com os outros na lida prática, lê-se o seguinte:

A ideia de dívida deve não apenas ultrapassar o âmbito das ocupações em seu prestar contas como também deve ser desligada de qualquer referência ao dever e à lei contra os quais alguém, numa falta, assume uma dívida. Pois nesse caso se determinaria, necessariamente, a dívida como falta, como violação de alguma coisa que deveria e poderia ser. Faltar, porém, significa não ser simplesmente dado. Falta no sentido de não ser simplesmente dado de dever é uma determinação ontológica do ser simplesmente dado. Nesse sentido, nada pode faltar de modo essencial à existência, não por ela ser perfeita mas porque seu caráter ontológico é inteiramente diverso de todo ser simplesmente dado ${ }^{8}$.

Temos que a negação, a fim de fundamentar o ser do Dasein, não pode levar consigo caracteres fáticos. Se a negação pode determinar a existência na qualidade de dívida, ela deve ser afastada de um ser simplesmente dado, de modo a não comprometer o fundamento ontológico. O ser do Dasein não está em dívida devido a uma causa prática, mas sim está em dívida de modo originário. Isso significa, que este ente é existência lançada e enquanto tal está sempre diante de possibilidades nas quais há sempre uma recusa, ou seja, há um não ou uma negação. Assim, além do fundamento existencial nadificante do Dasein, que se constitui a partir do ser-para-a-morte e do angustiar-se que se depara com a nulidade da existência ontológica, o fundamento deste ente em especial é originariamente também negativo. Ele é desde sempre o nada e a negação, pois ambos não podem ser a causa do fundamento do Dasein, mas sim o fundamento nulo e negativo do Dasein é que possibilita o nada e a negação das possibilidades existenciais.

${ }^{8}$ HEIDEGGER, M. Ser e Tempo. Partes I e II. Trad.: Marcia Sá Cavalcante Schuback. Rio de Janeiro: Vozes, 2009, p. 363.

\begin{tabular}{|c|c|l|l|c|c|}
\hline intuitio & $\begin{array}{c}\text { ISSN } \\
1983-4012\end{array}$ & Porto Alegre & Vol. $8-\mathrm{N}^{\circ} .2$ & $\begin{array}{c}\text { Dezembro } \\
2015\end{array}$ & p.128-145 \\
\hline
\end{tabular}


Antropologia filosófica: um paralelo entre o pensamento heideggeriano e o scheleriano em busca do ser do homem

Ao escolher pela possibilidade mais própria o Dasein apela para a consciência por meio de um escutar angustiante, pois é necessário que o Dasein abdique de uma identidade prática ou de um sentido prático até então presente na sua vida. Contudo, somente por meio da angústia, que se assemelha a uma perda de sentido do mundo e a uma estranheza singular, que ele pode existir sendo propriamente ele mesmo. É um modo silencioso no qual o Dasein pode aquietar-se, se retirar de todo o cotidiano impessoal, que era preenchido pelo alarido do falatório. Ainda que, antecipando a morte existencial a partir do modo mais próprio de existir, o Dasein continua no mundo, tal como lemos na seguinte passagem de Heidegger: “A decisão não desprende o Dasein, enquanto ser-si-mesmo mais próprio, de seu mundo, ela não isola num eu solto no ar. E como poderia, se o Dasein, no sentido de abertura própria, nada mais é propriamente do que ser-no-mundo?" ${ }^{\text {. }}$. Para se decidir pelo modo próprio de existir o Dasein não precisa se retirar da realidade que o circunda, mas sim projetar-se no modo autêntico da existência considerando essa possibilidade a partir do seu próprio entorno fático. Por fim, a negação do modo impróprio de existir torna possível o fundamento sólido para a questão do sentido ontológico e, ainda, traz à luz a compreensão de ser por meio do Dasein autêntico. Sendo assim, a negação do existenciário fático projeta o fundamento ontológico deste ente enquanto negação e nulidade.

Tal negação que se apresenta no interior da ontologia fundamental em Ser e Tempo também ocorre na obra de Scheler, mas antes de visar um fundamento ontológico do ser, ela procura a essência do homem para fundamentar a antropologia filosófica. Dado que para Scheler o ser humano é uma pessoa essencialmente espiritual e, como tal é capaz de idear, se segue que é em torno desse âmbito que encontramos a noção de negação. Pois bem, o ser humano com suas ciências positivas e empíricas pode analisar as causas da dor ou, pode ainda, analisar as representações que permanecem presas às coisas percebidas. Ele pode mais, como analisar separadamente as coisas abstratas das coisas concretas, já que ele é possuidor de uma inteligência técnica e de dedução. Porém, como pessoa essencialmente espiritual, o homem consegue colocar questões para si que a inteligência dedutora não é capaz. Por exemplo, a pessoa pode analisar a dor e perguntar-se o que é a dor em si mesma, afastando-se do fato da dor estar ali e agora.

Como possuidora de atos de ideação ${ }^{10}$ a pessoa pode conquistar um saber que supera os limites das experiências sensíveis. Este saber é a priori e significa o mesmo para todos os mundos possíveis. Ele serve para as ciências positivas como axiomas ou pressuposições superiores ou pode servir para a metafísica como uma abertura para o absoluto ser. Com esta distinção de saberes, Scheler separa os conhecimentos essenciais de ordem apriorística de conhecimentos existenciais de ordem empírica. Ao homem, por fim, cabe a capacidade de alcançar conhecimento essencialista, sem prender-se a

\footnotetext{
${ }^{9}$ HEIDEGGER, M. Ser e Tempo. Partes I e II. Trad.: Marcia Sá Cavalcante Schuback. Rio de Janeiro: Vozes, 2009, p. 379 .

${ }^{10}$ Tal conceito é abordado por Husserl na página 35 do capítulo 3 da obra Ideias para uma fenomenologia pura e para uma filosofia fenomenológica.
}

\begin{tabular}{|c|c|c|c|c|c|}
\hline intuitio & $\begin{array}{c}\text { ISSN } \\
1983-4012\end{array}$ & Porto Alegre & Vol.8 $-\mathrm{N}^{\circ} .2$ & $\begin{array}{c}\text { Dezembro } \\
2015\end{array}$ & p.128-145 \\
\hline
\end{tabular}


Antropologia filosófica: um paralelo entre o pensamento heideggeriano e o scheleriano em busca do ser do homem

experimentos e análises empíricas. Portanto, o homem como pessoa espiritual é capaz de intelecções essenciais, que partem, por sua vez, dos atos de ideação. Antes o homem era apenas um ser vivo entre outros seres que perseguiam seus extintos mais fundamentais, mas como pessoa espiritual o homem pode transcender a esfera do puro extinto natural para um nível no qual é capaz de compreender a si mesmo e compreender o mundo. Para saltar do nível natural e alcançar o nível da essência, a pessoa precisa ser capaz de idear um conhecimento puro, que é distinto dos conhecimentos já existes. Este salto é denominado por Scheler de suspensão do caráter de realidade. Ao negar a realidade das coisas, do mundo concreto e da efetividade ${ }^{11}$, a pessoa executa um ato de redução, ou seja, de desrealização.

As coisas do mundo nos aparecem de certa maneira, de modo que nunca captamos sua essencialidade. O que se capta, ao contrário, é seu modo de ser casual e de momento. Apenas a pessoa espiritual pode executar a negação desse estado natural e reduzir, com o ato de vontade pura, o impulso afetivo. E, assim, asceticamente vivenciar a vida, possuindo domínio e controle dos próprios impulsos oriundos das representações efetivas. Portanto, temos que o processo baseia-se no ato da vontade pura e no ato de ideação, com os quais a pessoa almeja uma outra realidade, a transcendente. Assim, o homem como pessoa pode elevar ou aprimorar suas pulsões reprimidas para uma atividade espiritual de autocompreensão e compreensão do mundo, desfazendo-se do ímpeto vital. Há na construção da antropologia filosófica uma negação para com os níveis mais primitivos da esfera vital, pois se segue que tirando as qualidades sensíveis das coisas, resta a impressão poderosa da vivência originária da realidade, alcançada pelo ato de redução que é antes de toda consciência, de toda representação e de toda percepção. Finalmente, a noção de negação presente no pensamento de Scheler pode ser mais bem compreendida no seguinte fragmento: “Comparando com o animal que sempre diz 'sim' ao que é real - mesmo aí onde ele se atemoriza e foge - o homem é aquele ‘que pode dizer não' ele é o 'asceta da vida', aquele que protesta eternamente contra toda mera realidade" $"$.

\section{A diferença entre a existência e a pessoa na constituição do mundo}

No parágrafo dois de Ser e Tempo Heidegger expõe o objetivo central da sua obra, a saber, a necessidade de colocar a questão fundamental acerca da possibilidade da investigação ontológica. A questão heideggeriana não investiga o sentido do ser, mas, antes disso, se o ser pode constituir uma questão possível. Toda investigação exige uma questão e uma busca, para esta se tornar possível é necessário um ponto de partida e uma direção prévia que possibilite tal questionamento. A importância de um ponto de partida prévio para a questão do sentido do ser necessita que um ente esteja dado, de algum

\footnotetext{
${ }^{11}$ Ver em SCHELER, M. A Posição do Homem no Cosmos. Rio de janeiro: Forense Universitária, 2003, p. 14.

${ }^{12}$ SCHELER, M. A Posição do Homem no Cosmos. Rio de janeiro: Forense Universitária, 2003, p. 53.
}

\begin{tabular}{|c|c|c|c|c|c|}
\hline intuitio & $\begin{array}{c}\text { ISSN } \\
1983-4012\end{array}$ & Porto Alegre & Vol.8 $-\mathrm{N}^{\circ} .2$ & $\begin{array}{c}\text { Dezembro } \\
2015\end{array}$ & p.128-145 \\
\hline
\end{tabular}


Antropologia filosófica: um paralelo entre o pensamento heideggeriano e o scheleriano em busca do ser do homem

modo, à disposição como aquilo que se dá de fato. A busca ontológica precisa, antes de mais nada, de um direcionamento guiado por um ente em particular, inserido no mundo ôntico. O ente em especial que proporciona o ponto de partida para essa investigação possui na sua constituição um modo singular de ser, em outras palavras, ele existe em um modo ôntico e em um modo ontológico. Esse ente é designado por Heidegger pelo termo Dasein. Ao elaborar a análise ôntica da existência não se deixa de lado a questão ontológica e transcendental das condições a priori do ser, porque é por essa via, justamente, que Heidegger almeja conquistar a compreensão do sentindo do ser em geral. É possível, a partir das estruturas intencionais do comportamento do Dasein, investigar acerca da interrogação do sentido do ser em um todo. A constituição dos comportamentos e relações ônticas deste ente partem de estruturas formais e, ontologicamente transcendentais, que buscam elaborar os critérios de possibilidade da questão acerca do ser.

Tendo em vista o objetivo geral de Heidegger, apresenta-se no escrito de 1927 a investigação sobre a existência do Dasein que se dá sempre em um mundo. A constituição de mundo é composta por três visualizações: em-um-mundo, na qual Heidegger questiona a estrutura ontológica de mundo e sua mundanidade; quem é o ente que está no modo da cotidianidade mediana; ser-em, que abarca a primeira visualização e procura a constituição ontológica deste em um mundo. A constituição de mundo é a priori, e é dela que toda a investigação da analítica existencial se guiará. No entanto, não é a constituição do mundo que dará a resposta do sentido do ser em geral, mas uma investigação mais ampla e profunda da propriedade e totalidade do ente em especial. Apesar da importância dessas três visualizações de mundo para a análise ontológica heideggeriana, nossa pesquisa centra-se apenas na segunda, isso significa que buscamos quem é o Dasein no seu modo cotidiano e mundano.

Quem é o Dasein? Ele é as condições formais pelas quais as determinações ontológicas fundamentais são dadas, diferente de um ente simplesmente dado como um martelo, uma caneta ou um machado. Dasein se constitui a partir de dois modos de ser, a saber: propriedade e impropriedade. O primeiro refere-se ao Dasein que escolhe interrogar pela sua existência. O segundo, diz respeito ao Dasein que se ocupa, que possui interesses, estímulos e prazeres referentes ao mundo como nos é apresentado. É, pois, neste segundo modo de existir que a nossa leitura avançará. Heidegger expõe, portanto, o quem do Dasein como aquele que pode não existir em si mesmo, ou ainda, o que nós mesmos somos na cotidianidade é definido por Heidegger como um eu que é a perda de si mesmo. O Dasein "é o impessoal e tudo que é instituído por este: um vasto e intrincado padrão - gerado e mantido pelo conformismo - de normas, disposições normais, costumes, escolhas, papéis, relações remissivas, instituições públicas, e assim por diante" ${ }^{, 13}$. O Dasein no contexto inautêntico de sua existência é um impessoal no mundo cotidiano, ele é o

${ }^{13}$ HAUGLAND, John. "Heidegger on Being a Person" in Noûs, Vol. 16, No. 1, 1982 A. P. A. Western Division Meetings (Mar., 1982), p. 15-26.

\begin{tabular}{|c|c|l|l|c|c|}
\hline intuitio & $\begin{array}{c}\text { ISSN } \\
1983-4012\end{array}$ & Porto Alegre & Vol.8 $-\mathrm{N}^{\mathrm{o} .2}$ & $\begin{array}{c}\text { Dezembro } \\
2015\end{array}$ & p.128-145 \\
\hline
\end{tabular}


Antropologia filosófica: um paralelo entre o pensamento heideggeriano e o scheleriano em busca do ser do homem

das Man, que não pergunta por razões e que não pode deliberar ${ }^{14}$. Encontramos, pois, no parágrafo 27 de Ser e Tempo a explanação heideggeriana acerca do quem cotidiano do Dasein. O Dasein é no mundo, ele reside no mundo com os outros entes, ele é ser-com outros na convivência cotidiana. Este modo de ser-nomundo não é algo determinado, é antes o que todos nós fizemos ao conviver no mundo, isso é mais bem dito no fragmento: "O quem não é este ou aquele, nem o si mesmo do impessoal, nem alguns e muito menos a soma de todos. O quem é o neutro, o impessoal" ${ }^{, 15}$. Nós como entes do tipo Dasein existimos impessoalmente nós mesmos, nós não possuímos primazia, todos somos nivelados como o público Öffentlichkeit -, isto é, somos todos e, ao mesmo tempo, qualquer um. Heidegger define o nosso modo habitual no qual nos encontramos no mundo como superficial e fácil, nós como impessoais somos todos uma grande multidão, lemos:

Na utilização dos meios de transporte público, no emprego dos meios de comunicação e notícias (jornal), cada um é como o outro. Este conviver dissolve inteiramente o próprio Dasein no modo de ser dos "outros", e isso de tal maneira que os outros desaparecem ainda mais em sua possibilidade de diferença e expressão. $\mathrm{O}$ impessoal desenvolve sua própria ditadura nesta falta de surpresa e de possibilidade de constatação ${ }^{16}$.

Na convivência cotidiana o Dasein ou, nós humanos, caracterizamo-nos como afastamento, medianidade, nivelamento, público e desencargo de ser. O modo impessoal manifesta o nosso não si mesmo e a nossa falta de reflexão. Nós como Das man mantemos em ordem as normas instituídas - a responsabilidade - através do regime do conformismo, somos um caso a partir do Dasein, que pode ser de várias formas mas nenhuma delas pode ser distinguida ou contabilizada. Como entes lançados no mundo, nós existimos em contextos já estabelecidos, que não permitem uma singularização. Somos todos padronizados, como é o caso, por exemplo, dos cidadãos massificados representados no quadro Operários de Tarsila do Amaral.

Entretanto, o Das man não é uma nadificação da facticidade, é antes um modo de ser dotado do caráter do Dasein, ou seja, nós somos existencialmente no mundo enquanto fenômeno originário que pertence a constituição ôntica-ontológica. Este modo de ser cotidiano apenas caracteriza quem nós somos como dotados de confusão, perdição, ofuscação, como todos e ao mesmo tempo como ninguém. Embora quem nós somos na cotidianidade não se define como algo simplesmente dado - é o caso dos utensílios como martelo e machado - o nosso si mesmo é disperso ou é uma perda de si mesmo. Contudo, o Das man

\footnotetext{
${ }^{14}$ TUGENDHAT, Ernest. Não somos de arame rígido: conferências apresentadas no Brasil em 2001. Canoas: Ulbra, 2002.

${ }^{15}$ HEIDEGGER, M. Ser e Tempo. Partes I e II. Trad.: Marcia Sá Cavalcante Schuback. Rio de Janeiro: Vozes, 2009, p. 183

${ }^{16}$ HEIDEGGER, M. Ser e Tempo. Partes I e II. Trad.: Marcia Sá Cavalcante Schuback. Rio de Janeiro: Vozes, 2009, p. 184.
}

\begin{tabular}{|c|c|l|l|c|c|}
\hline intuitio & $\begin{array}{c}\text { ISSN } \\
1983-4012\end{array}$ & Porto Alegre & Vol.8 $-\mathrm{N}^{\circ} .2$ & $\begin{array}{c}\text { Dezembro } \\
2015\end{array}$ & p.128-145 \\
\hline
\end{tabular}


Antropologia filosófica: um paralelo entre o pensamento heideggeriano e o scheleriano em busca do ser do homem

apresenta uma identidade perante todo o contexto cotidiano, mas é uma identidade meramente prática a partir dos comportamentos humanos. Embora a abordagem dss existências cotidianas em Heidegger apresente uma riqueza de caracteres ônticos, é Scheler que introduz a ideia do homem integralmente ligada a um mundo ôntico, mas sob uma nova perspectiva. Esta nova perspectiva caracteriza-se por uma abordagem exclusivamente antropológica na filosofia. Com a noção de pessoa, Scheler define o homem como aquele ser capaz de suspender seu mundo entorno - dos animais e vegetais - a fim de compreender sua essência e seu lugar peculiar.

O empreendimento de Scheler para alcançar a essência humana no interior da ontologia é marcadamente diversa da tarefa da ontologia formal husserliana, que subordina a fenomenologia ao ego puro, e é também diversa da ontologia heideggeriana, que pretende uma destruição da história da metafísica e que busca através da análise do ente - Dasein - o ser que está ai ${ }^{17}$. Ao contrário, em Scheler a essencialidade do homem é objeto de análise intelectual, algo oposto às ciências empíricas. Enquanto análise intelectual, o projeto enfoca a essência do ser humano corporal a partir de uma origem axiológica. Esta, por sua vez, possui na sua base a esfera da afetividade e dos atos valorativos, de modo que são eles a reconhecerem o que se dá na origem axiológica e não o contrário. O a priori da ética de Scheler é material - em oposição ao formalismo e subjetivismo kantiano - de modo que, como se observa na sua axiologia, não é o racionalismo ou a intelecção que fornecem o método para alcançar o sentido do homem e do cosmos, mas antes, são os atos autônomos e a afetividade como conteúdo a priori axiológico. Então, podemos afirmar, que a vida na cosmovisão não é um empirismo, é uma transcendentalidade metafísica porque possui uma estrutura a priori ordenada. Acima de tudo, o princípio scheleriano caracteriza-se como realista, pois tem como fundamento a vida e o espírito ${ }^{18}$.

Este espírito está ligado à pessoa, pois ela é o "centro ativo no qual o espírito aparece no interior das esferas finitas do ser"19. Em outras palavras, a pessoa é a forma concreta e real da existência do espírito. Scheler constrói com a antropologia filosófica um fundamento único do espírito e da vida no homem, ou seja, as preocupações por uma fundamentação ontológica tanto do homem quanto do cosmos ocorrem precisamente no homem, no qual espírito e vida seriam manifestações que juntam-se apenas no

\footnotetext{
${ }^{17}$ PINTOR RAMOS, Antonio. "Las esferas de ser" in El Humanismo de Max Scheler. Madri: La Editorial Catolica, 1978, p. 80.

18 'Uma palavra que certamente abarca concomitantemente o conceito de 'razão', mas que, ao lado do 'pensamento das ideias', também abarca concomitantemente um determinado tipo de 'intuição', a intuição dos fenômenos originários ou dos conteúdos essenciais, e, mais além, uma determinada classe de atos volitivos e emocionais tais como a bondade, o amor, o remorso, a veneração, a ferida espiritual, a bem-aventurança e o desespero, a decisão livre: a palavra "espírito"'. SCHELER, M. A Posição do Homem no Cosmos. Rio de janeiro: Forense Universitária, 2003 , p. 35.

${ }^{19}$ SCHELER, M. A Posição do Homem no Cosmos. Rio de janeiro: Forense Universitária, 2003, p. 35-36.

${ }^{13} \mathrm{O}$ título original das respectivas obras: Der Formalismus in der Ethik und die materiale Wertethik $(1913$ - 1916) e Wesen und Formen der Sympathie (1923).
}

\begin{tabular}{|c|c|l|l|c|c|}
\hline intuitio & $\begin{array}{c}\text { ISSN } \\
1983-4012\end{array}$ & Porto Alegre & Vol.8 $-\mathrm{N}^{\mathrm{o} .2}$ & $\begin{array}{c}\text { Dezembro } \\
2015\end{array}$ & p.128-145 \\
\hline
\end{tabular}


Antropologia filosófica: um paralelo entre o pensamento heideggeriano e o scheleriano em busca do ser do homem

homem e, simultaneamente, o ser originário adquiriria consciência de si mesmo também no homem. À vista disso, Scheler busca uma elevação da antropologia ao nível filosófico, isto é, a essência do homem a partir de uma base real, concreta, existente. Porém, para não constituir somente uma antropologia empírica, eleva-se a compreensão acerca da essência do homem à compreensão ontológica. Assim, há uma dupla dependência, enquanto que a reflexão antropológica pressupõe uma base ontológica, a compreensão ontológica pressupõe uma base antropológica. Dessa maneira Scheler unifica todas as áreas do saber científico com a filosofia, a fim de colocar a pergunta sobre o homem de uma maneira legítima. A ideia unitária do ser humano e a ideia do ser originário conquistam um lugar na consciência de si mesmo da pessoa humana.

Mas, para chegar a ideia central da antropologia filosófica, a saber, a ideia de pessoa, a análise inicia-se muito antes com o auxílio das ciências humanas, como a sociologia e a psicologia. Além disso, com o viver e com as obras do homem, Scheler passa a descrever o homem como um ser vivo. Ele elabora, detalhadamente, a variada forma de vida mais primitiva até a forma de vida mais complexa. E a vida, por sua vez, é entendida como a realidade originária e irredutível, que se manifesta em graus diversos do microcosmos ${ }^{20}$. Este mundo mais básico e elementar se baseia em graus evolutivos, são eles: o impulso afetivo, que é responsável pelo crescimento e reprodução dos vegetais; o instinto animal; a memória associativa presente em alguns animais e nos homens; por último, o grau da inteligência prática, ele manifesta-se nos homens e em certa medida nos animais superiores, mostra-se presente a partir de inovações que solucionam situações inesperadas ${ }^{21}$. Este mundo mais primitivo estabelece um entorno que determina-se através de uma visão limitada por conhecimentos dedutivos e por comportamentos impulsivos. Apesar disso, a diferença entre animal e homem não realizar-se-á no âmbito da biologia ou da psicologia, mas sim no interior da filosofia. Com uma mudança metafísica, Scheler posiciona o homem afastado de explicações científicas e situa-o em um lugar próprio no cosmos. Tal lugar que até então nem as ciências positivistas e nem o pensamento moderno ofereceu, mas que agora a antropologia filosófica propicia de forma privilegiada.

Este lugar estabelece o homem na qualidade de pessoa espiritual, isto é, um homem real com uma dimensão metafísica capaz de suspender o âmbito do microcosmos - Umwelt - em direção a um mundo no qual é capaz de visualizar a essência das coisas mesma e até de si mesmo. Neste mundo, distinto da esfera puramente vital e orgânica, o ser humano é capaz de desvincular-se de interesses casuais para idear, e a esta nova capacidade é determinada por Scheler da seguinte maneira:

\footnotetext{
${ }^{20}$ A estrutura do microcosmo, que se caracteriza pelo entorno do mundo psicofísico, está desenvolvida no primeiro capítulo da obra A posição do homem no cosmos.

${ }^{21}$ Os diferentes graus estruturam a parte da construção do mundo psicofísico presente no primeiro capítulo da obra $A$ Posição do Homem no Cosmos.
}

\begin{tabular}{|c|c|l|l|c|c|}
\hline intuitio & $\begin{array}{c}\text { ISSN } \\
1983-4012\end{array}$ & Porto Alegre & Vol.8 $-\mathrm{N}^{\circ} .2$ & $\begin{array}{c}\text { Dezembro } \\
2015\end{array}$ & p.128-145 \\
\hline
\end{tabular}


Antropologia filosófica: um paralelo entre o pensamento heideggeriano e o scheleriano em busca do ser do homem

O novo princípio encontra-se fora de tudo isto que podemos denominar "vida" no sentido mais amplo possível. O que torna o homem homem não é um novo estágio de uma forma de manifestação desta vida, da Psyche. Ao contrário, ele é um princípio oposto a toda e a cada vida em geral, também à vida no homem: um fato autenticamente novo que não pode ser absolutamente reduzido como tal à "evolução natural da vida", mas, se é que pode ser reduzida a algo, apenas ao fundamento único e supremo das coisas mesmas. Deste fundamento a "vida" é uma grande manifestação ${ }^{22}$.

No contexto em que a pessoa supera o horizonte vital, suas leis e suas relações, o homem passa a ter mundo - Welt -, ou seja, um macrocosmo no qual ele se encontra em liberdade e não mais conectado ao impulso das coisas psicofísicas ${ }^{23}$. Um tal mundo integra a pessoa à categoria de ato. Mas vale lembrar, contudo, que a pessoa enquanto ato não se realiza da mesma forma que um objeto. Na qualidade essencialista de atos evita-se a determinação de objeto ou coisa, pois a pessoa é e vive essencialmente em seus atos - volitivos ou emocionais. Por isso, é da essência da pessoa nunca se tornar um objeto de um ato de reflexão, isso é mais bem expresso no texto:

O espírito [...] - ele é pura atualidade, só tem seu ser na livre realização de seus atos. O centro do espírito, a pessoa, não é, portanto, nem um ser objetivo, nem um ser coisificado, mas apenas uma estrutura ordenadora de atos (essencialmente determinada) que leva a termo constantemente a si mesma. A pessoa só é em seus atos e através deles" ${ }^{, 4}$.

Ao executar a suspensão do caráter de realidade das coisas ocorre um duplo benefício para o espírito e para a esfera vital: o espírito opera na realidade vivenciando-se e a esfera vital se aprimora na medida em que se espiritualiza. Com este mútuo benefício Scheler parece alcançar um equilíbrio entre a vida e o espírito, pois ambos, simultaneamente, colocam-se em atividade e realidade, mesmo que possuam essências distintas. Além do mais, ambos se tornam efetivos a partir dos atos de ideação presentes na essência da pessoa. Esta, por sua vez, representa um princípio superior e irredutível à vida, ela torna o ser humano capaz de desvincular-se de seu interesse concernente às coisas ao seu redor. Ao situar o homem na esfera real e metafísica, Scheler parece ter fixado na filosofia uma concepção de antropologia que satisfaz as exigências de uma disciplina severa e metódica. A noção de pessoa juntamente com um método reflexivo faz com que a antropologia filosófica não seja taxada de ciência que apela para as investigações empíricas e relativistas. A investigação acerca do ser humano e de seu lugar especial no universo supera a ideia de uma vida constituída apenas de junções factuais, evolutivas e de sobrevivência, para uma

\footnotetext{
${ }^{22}$ SCHELER, M. A Posição do Homem no Cosmos. Rio de janeiro: Forense Universitária, 2003, p.35.

${ }^{23}$ A liberdade do homem é instituída a partir de uma única estrutura ilacerável que lhe é própria, a saber: reunião, autoconsciência e capacidade objetiva de resistência pulsional originária. A estrutura do mundo do homem caracterizado por uma liberdade é elaborada, principalmente, a partir da página 38 da Posição do Homem no Cosmos, contrastando com o mundo seguro e limitado da esfera vital.

${ }^{24}$ SCHELER, M. A Posição do Homem no Cosmos. Rio de janeiro: Forense Universitária, 2003, p. 45.
}

\begin{tabular}{|c|c|c|c|c|c|}
\hline intuitio & $\begin{array}{c}\text { ISSN } \\
1983-4012\end{array}$ & Porto Alegre & Vol.8 $-\mathrm{N}^{\mathrm{o} .2}$ & $\begin{array}{c}\text { Dezembro } \\
2015\end{array}$ & p.128-145 \\
\hline
\end{tabular}


Antropologia filosófica: um paralelo entre o pensamento heideggeriano e o scheleriano em busca do ser do homem

visualização da vida como ela é em si mesma, uma vida contemplativa na qual o ser se origina. Nessa visão aprimorada da vida o homem como pessoa compreende-se e vive perante as mais diversas manifestações humanas de modo sereno e equilibrado.

\section{Considerações Finais}

O que vimos até aqui baseia-se na análise em torno da antropologia filosófica, que desde os escritos do século XIX comportou severas críticas. No primeiro momento há uma visão geral da antropologia filosófica no interior da filosofia, isto é, seu surgimento, seus percalços e sua ascendência nos escritos de Scheler. Porém, o filósofo que contribui para uma ideia negativa de uma antropologia filosófica foi Heidegger, pois ele fez a antropologia filosófica aparecer em duas das suas maiores obras para mostrar como o método da antropologia filosófica era falho e impreciso. Em um segundo momento encontramos a explanação de uma possível elaboração da antropologia filosófica, a partir da obra $A$ posição do Homem no Cosmos, juntamente com o nítido afastamento heideggeriano de qualquer terminologia antropológica nos seus escritos. Nunca foi o objetivo de Heidegger transformar sua analítica existencial em uma espécie de estudo sobre o ser humano, se houvesse tal interpretação, essa seria equivocada e mal sucedida de acordo com o filósofo. No terceiro momento trouxemos a leitura de uma noção que aparece tanto em Scheler quanto em Heidegger, a de negação. Ambos os filósofos compartilham da ideia de negação no interior de suas argumentações. Enquanto que Heidegger buscou a possibilidade da questão ontológica, Scheler investigou a essência humana na ontologia, contudo, para os dois pensadores o conceito de negação possibilitou as respectivas análises filosóficas. Para Heidegger a noção de negação está conectada à abertura do apelo à consciência, suspendendo o modo cotidiano da existência e mostrando o fundamento ontológico negativo do ser do Dasein. Já para Scheler, a noção de negação diz respeito ao ato de redução, o qual suspende a esfera vital do mundo tido como Umwelt.

Por fim, no último e quarto momento é elaborado a estrutura ontológica do mundo tendo em vista o pensamento de Scheler e de Heidegger, isto é, como cada um estruturou o mundo em que vivemos. À medida em que o mundo para Heidegger possui um caráter existencial, Scheler o vê em graus de naturezas diversas, nos quais as plantas ocupam o grau inferior e o ser humano o grau superior. No entanto, diferente dos existenciais da investigação heideggeriana, no mundo metafísico o homem pode vir a possuir uma essência própria que o singularize, sem perder-se nas instituições mundanas, para isso basta que ele efetue a redução e suspenda as mais gerais preocupações da esfera vital. A partir desta análise do mundo percebemos que ele é uma estrutura básica para ambos os pensadores. É a partir do mundo e com o mundo que a pessoa e o Dasein constituem, de uma maneira crucial, toda a elaboração da análise filosófica investigativa. Para a antropologia filosófica, seu solo seguro é encontrado graças a uma busca incessante

\begin{tabular}{|c|c|c|c|c|c|}
\hline intuitio & $\begin{array}{c}\text { ISSN } \\
1983-4012\end{array}$ & Porto Alegre & Vol.8 $-\mathrm{N}^{\circ} .2$ & $\begin{array}{c}\text { Dezembro } \\
2015\end{array}$ & p.128-145 \\
\hline
\end{tabular}


Antropologia filosófica: um paralelo entre o pensamento heideggeriano e o scheleriano em busca do ser do homem

por um ser humano ontologicamente situado na filosofia, mesmo com os empecilhos das ciências empíricas emergentes da época.

Ao final do século XIX e início do século XX a antropologia filosófica scheleriana surge após um período de guerras, em que a identidade do povo estava abalada e, consequentemente, também toda uma cultura. Mas, é justamente diante deste contexto que a busca por uma ideia de homem a partir da perspectiva filosófica, tendo em vista a predominância das ciências naturais, mostrou-se algo inovador. Além disso, demonstrava a preocupação de Scheler quanto ao homem e, em especial, sua identidade perante o cosmos existente. Ele foi capaz de desenvolver uma antropologia nos parâmetros filosóficos jogando com a ideia de metafísica. Sob olhar de alguns, no entanto, como já é sabido, sua antropologia filosófica somente podia ser lida nos termos de uma ontologia regional (Heidegger), ou ainda, não possuía um método rigorosamente filosófico já que tratava de um ente concreto (Husserl). Porém, enquanto que a metafísica tradicional incorria em "delírios especulativos", a metafísica de Scheler nos abriu a possibilidade de fundamentar o homem perante a sua esfera espiritual e a esfera concreta da pessoa.

As objeções à antropologia eram as mais diversas. A teoria husserliana, por exemplo, considerou a antropologia como uma filosofia mundana, como uma ciência do mundo natural, a qual não representava um possível método filosófico. Já Heidegger condenou a antropologia na categoria de segunda ordem, pois o ser humano é definido apenas em relação à primeira categoria, a saber, a categoria do ser. Todavia, apesar dessas posições contrárias à antropologia, Scheler, por outro lado, investigou a antropologia filosófica definindo o ser humano em relação ao fundamento cósmico absoluto e também em relação à esfera do ser vivo. Diferentemente de Husserl e Heidegger, na visão scheleriana a antropologia é uma coparticipação entre o absoluto e a existência humana. Scheler fixa a antropologia filosófica na estrutura metafísica tornando-a uma disciplina genuinamente filosófica de primeira categoria. Por isso, a antropologia filosófica constituiu-se como disciplina sólida e independente nos escritos de Scheler. A partir da noção scheleriana de espírito, introduzida na análise acerca do homem, a antropologia filosófica é marcadamente diferenciada de um fundamento reducionista ou insuficiente, pois baseia-se em um fundamento absoluto e metafísico. Além disto, a antropologia, enquanto estabelecida nos parâmetros da filosofia, é tida como autônoma, justamente pelo fato do espírito constituir-se independentemente de uma esfera psíquica pertencente ao âmbito do mundo natural.

A partir da obra de 1928 a antropologia filosófica se estabelece enquanto uma disciplina filosófica autônoma e rigorosa. Ao fundamentar o estudo do homem nos patamares de uma disciplina filosófica, Scheler inicia uma ideia unitária de ser humano e de seu lugar ontológico originário. A ontologia de Scheler traz como novidade seu não fundamentalismo, isto é, a investigação ontológica pressupõe uma base antropológica e filosófica. A ontologia só pode ser alcançada com uma ampla busca pelo homem ou a ontologia e a antropologia filosófica se complementam na explicação do homem e de seu lugar no

\begin{tabular}{|c|c|c|c|c|c|}
\hline intuitio & $\begin{array}{c}\text { ISSN } \\
1983-4012\end{array}$ & Porto Alegre & Vol.8 $-\mathrm{N}^{\circ} .2$ & $\begin{array}{c}\text { Dezembro } \\
2015\end{array}$ & p.128-145 \\
\hline
\end{tabular}


Antropologia filosófica: um paralelo entre o pensamento heideggeriano e o scheleriano em busca do ser do homem

panorama do ser. Quanto à metafísica que perpassa a antropologia filosófica, pode-se dizer que ela não é exclusiva, ou seja, há a presença constante do plano sensível e do plano espiritual, e quem media essa relação é o homem. Portanto, a fim de resgatar um método genuinamente filosófico, diferente do método racionalista e empirista, a antropologia filosófica possuía duas tarefas, a saber, precisava lidar com as ciências empíricas/naturais do homem e ainda, era necessário legitimar a antropologia no interior da filosofia. Scheler foi capaz de estabelecer a ideia una e essencial de homem no que há de mais próprio na sua antropologia, a saber, uma transcendentalidade metafísica.

\section{Referências}

CUSINATO, G. Alcuni elementi per un'ontologiadella persona a partire da Max Scheler. Milano: Vita e Pensiero, 2009.

HAUGLAND, J. Heidegger on Being a Person in Noûs, Vol. 16, No. 1, 1982 A. P. A. Western Division Meetings (Mar.1982), pp. 15-26.

HEIDEGGER, M. Ser e Tempo. Partes I e II. Marcia Sá Cavalcante Schuback. Rio de Janeiro: Vozes, 2009. Sein und Zeit. Tübingen: Max Niemeye Verlag, 2006.

. Kant y el Problema de la Metafísica. México: Fondo de Cultura Econômica, 1996.

HUSSERL, E. Ideias para uma fenomenologia pura e para uma filosofia fenomenológica. Trad. Márcio Suzuki. Aparecida, SP: Ideias \& Letras, 2006.

KANT, I. Crítica da Razão Pura. Trad. Valerio Rohden e Udo Baldur Moosburger. São Paulo: Nova Cultura Ltda, 1999.

PINTOR RAMOS, A. El Humanismo de Max Scheler. Madri: La Editorial Catolica, 1978.

SCHNÄDELBACH, H. La Filosofia en Alemania, 1831-1933. Madrid: Catedra, 1991.

SCHELER, M. A Posição do Homem no Cosmos. Trad. Marco Antônio Casanova. Rio de janeiro: Forense Universitária, 2003.

. Die Stellung des Menschen im Kosmos. Darmstadt: Otto Reichl Verlag, 1928.

Ética. Trad. Hilario Rodrígues Sanz. Madrid: Caparrós, 2001.

Essência y Formas de la Simpatía. Trad. José Gaos. Buenos Aires: Losada, 2004.

STEIN, E. Antropologia filosófica - Questões Epistemológicas. Ijuí: Unijuí, 2006.

TUGENDHAT, E. Antropologia como filosofia primeira. In: OLIVEIRA, Nythamar de; SOUZA, Draiton Gonzaga de (Orgs.). Hermenêutica e filosofia primeira. Ijuí: Unijuí, 2006.

Recebido em: 09/09/2014

Aprovado para publicação em: 12/11/2015

\begin{tabular}{|c|c|c|c|c|c|}
\hline intuitio & $\begin{array}{c}\text { ISSN } \\
1983-4012\end{array}$ & Porto Alegre & Vol.8 $-\mathrm{N}^{\circ} .2$ & $\begin{array}{c}\text { Dezembro } \\
2015\end{array}$ & p.128-145 \\
\hline
\end{tabular}

